London, UK

jo.best@journalist.com

Cite this as: BMJ 2021;374:n2280 http://dx.doi.org/10.1136/bmj.n2280 Published: 22 September 2021

BRIEFING

\title{
What's Health Data Research UK doing to help tackle covid-19?
}

The UK's national institute for data science wants datasets to be more accessible to researchers in order to improve patient outcomes. Jo Best reports

Jo Best freelance journalist and doctor

\section{What has HDR UK been doing during the pandemic?}

Last year, the government's chief scientific adviser, Patrick Vallance, identified the areas of covid-19 research in which the UK needed to bolster its capabilities. ${ }^{1}$ Among these were "data and connectivity," and Vallance charged Health Data Research UK (HDR UK) and the Office for National Statistics (ONS) with making health and administration data available for linking and use in covid-19 research.

"At the beginning of the pandemic everyone wanted to help, but we saw complete fragmentation of the research community," Andrew Morris, director of HDR UK, told The BMJ. "There was also no prioritisation of the research questions that were important for pandemic response, and certainly no cohesive and coherent way of accessing data."

\section{What progress has been made?}

HDR UK and the ONS have created 88 covid-19 specific datasets related to vaccines, viral genome, and testing, available for use within "trusted research environments"-secure spaces for researchers to access sensitive data. HDR UK's work has facilitated the publication of 200 research papers on covid-19, including research using data from 5.4 million people ${ }^{2}$ that showed covid vaccines reduce hospital admissions and a study that showed that infection presents more risk of thrombocytopenia and thromboembolic events than vaccination. ${ }^{3}$ Over 1000 other papers are available as non-peer reviewed preprints.

\section{How are patients involved?}

HDR UK has been reporting fortnightly to the government's Scientific Advisory Group for Emergencies to help prioritise research questions. HDR UK's public advisory board highlights which questions are important to the public. The board noted public interest in the impact on social care, for example, resulting in more research funding for this area. The board also gauges public attitudes towards how their data are used, both in particular studies and more broadly. This information shapes policies on information governance, informs study designs, and encourages transparency in research.

HDR UK and others have investigated how to involve patients with covid-19 rapidly in clinical trials. The Principle trial, ${ }^{4}$ for example, needed to identify and enrol participants within $24-48$ hours of a positive covid antigen test. HDR UK's patient and public panels and networks provided feedback on the ethics of the study's proposed method of releasing would-be recruits' data so that they could be invited by researchers to join the study.

\section{Why was HDR UK created?}

Troves of existing health data are isolated in siloes, aren't standardised, or are poorly described-and therefore may be hard for researchers to access or use. HDR UK was created in 2018 by 10 funders, including the Medical Research Council, the Wellcome Trust, and the National Institute for Health Research, to improve the quality of large health datasets and make them findable by, and accessible to, researchers. HDR UK hopes researchers will ultimately be able to use data that are better described and shared to improve patient care and outcomes.

\section{What is the Health Data Alliance?}

Convened by HDR UK, this is a group of over 60 data custodians, including NHS trusts, research institutes, and research funding charities, that share their own health data and help other organisations to improve theirs. The alliance identifies and disseminates best practice for data sharing and provides information on the adoption of common standards, tools, and approaches to governance and public engagement to promote ethical data sharing and use. Over 600 datasets from alliance members, as well as 150 tools covering everything from questionnaires to machine learning programmes, are available. ${ }^{5}$

\section{How else can health data sharing be improved?}

Researchers will increasingly need access to, and to be able to link, datasets from outside and within public health. Using data from, say, environmental and social sources, researchers will be able to understand better the impact of non-health variables on health. HDR UK is working with Administrative Data UK, which handles public sector data. HDR UK also aims to forge global partnerships to make data accessible across borders in a trustworthy way.

\section{Provenance and peer review: Commissioned; not externally peer reviewed.}

Competing interests: I have read and understood BMJ policy on declaration of interests and have no relevant interests to declare.

Government Office for Science, Vallance P. Letter. 28 October 2020 https://committees.parliament.uk/publications/3400/documents/32493/de fault 
2 Vasileiou E, Simpson CR, Shi T, et al. Interim findings from first-dose mass COVID-19 vaccination roll-out and COVID-19 hospital admissions in Scotland: a national prospective cohort study. Lancet 2021;397:1646-57. doi: 10.1016/S0140-6736(21)00677-2 pmid: 33901420

3 Health Data Research Innovation Gateway. www.healthdatagateway.org

4 Principle trial. www.principletrial.org

5 Hippisley-Cox J., Patone M, Mei XW, et al. Risk of thrombocytopenia and thromboembolism after covid-19 vaccination and SARS-CoV-2 positive testing: self-controlled case series study. BMJ 2021;374:n1931. doi: 10.1136/bmj.n1931 pmid: 34446426

This article is made freely available for use in accordance with BMJ's website terms and conditions for the duration of the covid-19 pandemic or until otherwise determined by BMJ. You may use, download and print the article for any lawful, non-commercial purpose (including text and data mining) provided that all copyright notices and trade marks are retained. 